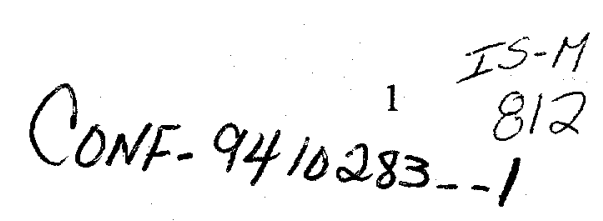

Submitted to Proceedings of the 17th International Taniguchi Symposium on Theoretical Physics on "Spectroscopy of Mott Insulators and Correlated Metals", Shima, Japan, 24-29 October 1994. To be published by Springer-Verlag, Heidelberg, as a volume in the Springer Series in Solid-State Sciences.

\title{
Superconductivity, Magnetism and Metal-Insulator Transitions in Some Ternary and Pseudoternary 3d-, 4d- and 5d-Metal Oxides
}

D. C. Johnston a, T. Ami ${ }^{\mathrm{b}, *}$, F. Borsa ${ }^{\mathrm{a}}$, M. K. Crawford ${ }^{\mathrm{b}}$, J. A. Fernandez-Bacac, K. H. Kim ${ }^{a}$, R. L. Harlow ${ }^{b}$, A. V. Mahajan ${ }^{\text {a,t }, ~ L . ~ L . ~ M i l l e r ~}{ }^{\text {a }}$, M. A. Subramanian ${ }^{b}$, D. R. Torgeson ${ }^{a}$, and Z. R. Wang ${ }^{a}$

${ }^{\mathrm{a} A m e s}$ Laboratory and Department of Physics and Astronomy Iowa State University, Ames, Iowa 50011, U.S.A.

bDuPont, Wilmington, Delaware 19880, U.S.A.

'Solid State Division, MS6393, Oak Ridge National Laboratory P.O. Box 2008, Oak Ridge, Tennessee 37831, U.S.A.

\begin{abstract}
Electron correlation effects have been found to be particularly important in metallic $\mathrm{LiV}_{2} \mathrm{O}_{4}$ and possibly $\mathrm{Sr}_{2} \mathrm{Ir}_{1-\mathrm{x}} \mathrm{Ru}_{\mathrm{x}} \mathrm{O}_{4}(\mathrm{x}>0.7)$, but not in metallic $\mathrm{Sr}_{1-\mathrm{x}} \mathrm{La}_{\mathrm{x}} \mathrm{VO}_{3}(\mathrm{x}<0.7)$, and they cause the compounds $\mathrm{Sr}_{2} \mathrm{IrO}_{4}$ and $\mathrm{ZnV}_{2} \mathrm{O}_{4}$ to be (Mott-Hubbard) insulators. The $\mathrm{LiV}_{2} \mathrm{O}_{4}$ spinel compound is especially interesting, because the $\mathrm{V}$ ions exhibit rather clear local moment $(S=1 / 2)$ behavior even though the compound is a metal.
\end{abstract}

\section{Introduction}

Prior to 1986 when the high superconducting transition temperature $\left(T_{c}\right)$ in layered cuprates with the $\mathrm{K}_{2} \mathrm{NiF}_{4}$ structure was discovered by Bednorz and Müller [1], the number of distinct superconducting oxide compounds was very small compared to the $\sim 10^{3}$ superconducting intermetallic compounds and elements. With the exception of the compounds $\mathrm{TiO}\left(\mathrm{T}_{\mathrm{c}}<2.3 \mathrm{~K}\right)$ and $\mathrm{NbO}\left(\mathrm{T}_{\mathrm{c}}<1.4 \mathrm{~K}\right)$, all of the superconducting oxides were ternary or higher-component phases grouped in five general classes in which three or more distinct crystallographic sites were occupied: the tungsten bronzes $\mathrm{A}_{\mathrm{x}} \mathrm{WO}_{3}\left(\mathrm{~T}_{\mathrm{c}}<7 \mathrm{~K}\right.$ for $\left.\mathrm{Rb}_{\sim 0.1} \mathrm{WO}_{3}\right)$, the perovskites $\mathrm{BaPb}_{1-\mathrm{x}} \mathrm{Bi}_{\mathrm{x}} \mathrm{O}_{3}$ $\left(\mathrm{T}_{c}<13 \mathrm{~K}[2]\right)$ and doped $\mathrm{SrTiO}_{3}\left(\mathrm{~T}_{c}<1 \mathrm{~K}\right)$, the clathrate compounds $\left(\mathrm{Ag}_{7} \mathrm{O}_{8}\right) \mathrm{X}$ $\left(T_{c}<1.5 \mathrm{~K}\right)$, where $\mathrm{X}$ is a monovalent anion, and the cubic spinel compound $\mathrm{LiTi}_{2} \mathrm{O}_{4}\left(\mathrm{~T}_{c}<13.7 \mathrm{~K}\right)[3]$. Various studies indicated that $\mathrm{LiTi}_{2} \mathrm{O}_{4}$ is a conventional $B C S d$-band superconductor [3-5]. The reason that there were so few oxide superconductors is that most oxides are not metallic at low temperatures, a property which up to now is a prerequisite for superconductivity to occur. The 3d-cations in insulating 3d-metal oxides tend to carry local magnetic moments and to order antiferromagnetically. Further, superconductivity was generally found to be absent in compounds containing a crystallographically ordered array of local moments on 


\section{DISCLAIMER}

Portions of this document may be illegible in electronic image products. Images are produced from the best available original document. 
the same sublattice of the structure on which superconductivity resides, irrespective of whether long-range magnetic ordering occurred. The conventional wisdom also held that in seeking new high- $T_{c}$ (defined at that time as $T_{c} \gtrsim 20 \mathrm{~K}$ ) superconductors, one should try to maximize the density of states at the Fermi energy $D\left(E_{F}\right)$, thereby enhancing the electron-phonon interaction responsible for (conventional) superconductivity. This in turn mandated incorporating transition metals in the compounds and ruled out the perovskite and related structures (such as the newer high- $T_{c}$ layered cuprates!) because oxygen ions lie directly between nearest neighbor metal ions; hence, if such a material were to be metallic, the electronic bands at the Fermi energy would presumably have to be formed from an intimate mixture of the metal and the oxygen $p$ orbitals, resulting in low $\mathrm{D}\left(\mathrm{E}_{\mathrm{F}}\right)$ and $\mathrm{T}_{\mathrm{c}}$. Indeed, doped $\mathrm{SrTiO}_{3}$ with the perovskite structure has a maximum $\mathrm{T}_{\mathbf{c}}$ of $<1 \mathrm{~K}$ [6]. Also, as one attempts to increase the $\mathrm{D}\left(\mathrm{E}_{\mathrm{F}}\right)$ and thereby the electron-phonon interaction, lattice instabilities ultimately set in which limit the attainable electron-phonon interaction and $\mathrm{T}_{c}$. The relatively high $\mathrm{T}_{\mathrm{c}}$ of $\mathrm{BaPb}_{1-\mathrm{x}} \mathrm{Bi}_{\mathrm{x}} \mathrm{O}_{3}\left(\mathrm{~T}_{\mathrm{c}}<13 \mathrm{~K}\right.$ [2]) was anomalous within this phenomenological framework.

In view of the above background, the discovery of superconductivity at $\sim 35 \mathrm{~K}$ in the layered perovskite-like cuprates by Bednorz and Müller and the subsequent increase in $T_{c}$ in similar materials by others to the present maximum of $\approx 164 \mathrm{~K}$ [7] is remarkable. With the advent of these cuprate superconductors, many of the above ideas had to be radically revised. The structures of all the presently known high $T_{c}$ cuprates contain $\mathrm{CuO}_{2}$ planes as in the prototypical $\mathrm{K}_{2} \mathrm{NiF}_{4}$-type "parent" compound $\mathrm{La}_{2} \mathrm{CuO}_{4}$ [8]. Features of these compounds of central interest to this paper are that the parent (undoped) insulating member of each system contains $\mathrm{Cu}^{+2}\left(\mathrm{~d}^{9}\right)$ cations with spin $S=1 / 2$ which order antiferromagnetically at $T_{N} \leqslant 550 \mathrm{~K}$, where strong dynamic short-range antiferromagnetic (AF) order occurs above $T_{N}$, and that shortrange $\mathrm{AF}$ correlations survive in the $\mathrm{CuO}_{2}$ planes of the doped metallic superconducting compositions $[9,10]$. It is widely believed that the superconductivity occurs in the $\mathrm{CuO}_{2}$ layers and therefore develops in the presence of, and is perhaps due to, the short-range $\mathrm{AF}$ order of the $\mathrm{Cu}$ spins; this is a radical departure from the systematics of superconductivity in conventional superconductors. We have carried out a variety of measurements on other $3 \mathrm{~d}$-, $4 \mathrm{~d}$ - and $5 \mathrm{~d}$-transition metal oxides to search for similarities and differences with the properties of the cuprates, in the hope of both elucidating aspects of the properties of the cuprates crucial to their magnetic character and high $T_{c}$ 's and of finding new high $T_{c}$ superconductors. In the cases of vanadium oxides, we were interested in $\mathrm{V}^{+4} / \mathrm{V}^{+3}\left(\mathrm{~d}^{\mathrm{l}} / \mathrm{d}^{2}\right)$ systems because they correspond to the electron analogue of the formally $\mathrm{Cu}^{+2} / \mathrm{Cu}^{+3}\left(\mathrm{~d}^{9} / \mathrm{d}^{8}\right)$ layered cuprates containing 1 or 2 holes in the $\mathrm{Cu}$ d-shell. In the following, we give some background and outline our work on some of these systems.

\section{Metallic $\mathrm{LiV}_{2} \mathrm{O}_{4}$}

Apart from $\mathrm{LiTi}_{2} \mathrm{O}_{4}$, the only other transition metal spinel compound which remains metallic to low temperatures is $\mathrm{LiV}_{2} \mathrm{O}_{4}$, as shown from resistivity measurements on single crystals [11]. The formal oxidation state of both the $T i$ and $V$ cations is +3.5 . Since the cations in each compound are crystallographically ordered and equivalent, one cannot assign +3 or +4 oxidation states to particular $\mathrm{Ti}$ or $\mathrm{V}$ cations, and the non-integral oxidation states demand that the compounds must be metallic, as observed. In the case of the $\mathrm{Ti}$ spinel, one formally has $\mathrm{d}^{0.5} \mathrm{Ti}$ ions. This $1 / 2$ electron per Ti atom must be itinerant (metallic) in an ionic picture, which has been verified by band structure calculations [5]. For the $V$ spinel, one formally has $d^{1.5} \mathrm{~V}$ ions. Part of these $1.5 \mathrm{~d}$-electrons $/ \mathrm{V}$ ion must contribute to the metallic conductivity. In contrast to the temperature $(T)$ independent Pauli paramagnetism 
shown by $\mathrm{LiTi}_{2} \mathrm{O}_{4}$ [3], $\mathrm{LiV}_{2} \mathrm{O}_{4}$ exhibits a Curie-Weiss magnetic susceptibility $\chi(T)=C /(T-\theta)$, with Curie constant $C \approx 0.47 \mathrm{~cm}^{3} \mathrm{~K} /$ mole $\mathrm{V}$ and Weiss temperature $\theta=-30$ to $-60 \mathrm{~K}[12]$, and does not become superconducting above $1.5 \mathrm{~K}$ [3]. The Curie constant is expressed as $C=\mathrm{N}_{A} \mu_{\text {eff }}{ }^{2} / 3 \mathrm{k}_{B}$, where $\mathrm{N}_{\mathrm{A}}$ is Avogadro's number, $\mu_{e f f}$ is the effective moment of a $V$ ion and $k_{B}$ is Boltzmann's constant. The above $C$ yields $\mu_{\text {eff }}=1.94 \mu_{B} / V$ ion, somewhat greater than the value $\mu_{\text {eff }}=g \mu_{B}[S(S+1)]^{1 / 2}=1.73 \mu_{B} / V$ ion expected for a spin $S=1 / 2$ ion with gyromagnetic factor $\mathrm{g}=2$. Thus, the $1.5 \mathrm{~d}$-electrons per vanadium atom apparently partition into $\approx 0.5$ metallic and $\approx 1.0$ localized d-electrons. The Curie-Weiss susceptibility and the negative sign of $\theta$ correspond to antiferromagnetic interactions between the local vanadium magnetic moments. Remarkably, the $1.5 \mathrm{~d}$ electrons originating from the same $t_{2} g$ crystal field levels of the $V$ atom are responsible for both the metallic character and the local moment magnetic behavior.

In contrast to $\mathrm{LiV}_{2} \mathrm{O}_{4}$, the spinel compound $\mathrm{ZnV}_{2} \mathrm{O}_{4}$, containing $\mathrm{V}$ in the $\mathrm{d}^{2}$ configuration, is a semiconductor with activation energy $\approx 0.20 \mathrm{eV}$ [13] due to strong electron correlation effects. The $\mathrm{ZnV}_{2} \mathrm{O}_{4}$ spinel shows antiferromagnetic ordering at $\mathrm{T}_{\mathrm{N}} \approx 45 \mathrm{~K}$ with an ordered (staggered) moment at $4.2 \mathrm{~K}$ of $\langle\mu\rangle=(0.8 \pm 0.3)$ $\mu_{\mathrm{B}} N$ ion [14]. A similar value was obtained for the spinel $\mathrm{MgV}_{2} \mathrm{O}_{4}[(1.1 \pm 0.1)$ $\mu_{B} / V$ ion] [14]. Since the $V$ ions presumably have spin $S=1$, one would expect $\langle\mu\rangle \approx \mathrm{gS} \mu_{\mathrm{B}} \approx 2 \mu_{\mathrm{B}} / \mathrm{V}$ ion for $\mathrm{g} \approx 2$; the reason for the discrepancies between the experimental values and the latter estimated value is not clear.

We have carried out $\chi(\mathrm{T})$ and ${ }^{7} \mathrm{Li}$ nuclear magnetic resonance (NMR) measurements on $\mathrm{LiV}_{2} \mathrm{O}_{4}$ to further characterize its magnetic properties [15]. The sample was prepared using solid state reaction $[3,4]$. The lattice parameter was found to be $8.235 \AA$, in agreement with previous reports [13]. The $\chi(T)$ measurements were carried out with a commercial SQUID magnetometer. The ${ }^{7} \mathrm{Li} N M R$ measurements were performed with a coherent pulse Fourier Transform spectrometer at variable frequency (applied magnetic field $H=10-82 \mathrm{kG}$ ) from 4.2 to $300 \mathrm{~K}$.

As shown in Fig. 1, the molar susceptibility $\chi_{M}(T)$ was found to follow a CurieWeiss law from $10 \mathrm{~K}$ to $300 \mathrm{~K}$, with Curie constant $\mathrm{C}=0.535 \mathrm{~cm}^{3} \mathrm{~K} /$ mole $\mathrm{V}$, corresponding to $\mu_{\text {eff }}=2.06 \mu_{\mathrm{B}} / \mathrm{V}$ atom, and Weiss temperature $\theta=-35.4 \mathrm{~K}$, comparable to previous results [12].

The ${ }^{7} \mathrm{Li}$ NMR linewidth is found to be field-dependent, indicating that the broadening is inhomogeneous, arising from a distribution of local fields due to the presence of localized moments at the $V$ site. Both the linewidth, $\Delta v$, and the line shift, $K$, are temperature dependent and are re;ated to $\chi_{M}$ as shown in Figs. 2(a-d). From theory, one expects

$$
\Delta v=2\left(M_{2}\right)^{1 / 2}=2\left[M_{2}{ }^{d i p}+\left(A_{h f} \chi_{M} \gamma_{n} H\right)^{2}\right]^{1 / 2},
$$

where $\mathrm{M}_{2}$ dip is the Van Vleck nuclear dipolar second moment, $\mathrm{A}_{\mathrm{hf}}$ is the nuclearelectron dipolar hyperfine interaction and $\gamma_{n}=2 \pi(1655 \mathrm{~Hz} / \mathrm{Gauss})$ is the gyromagnetic ratio of the ${ }^{7} \mathrm{Li}$ nucleus. The theoretical estimated value of $\mathrm{M}_{2}{ }^{\text {dip }}$ is $8.4 \times 10^{6} \mathrm{~Hz}^{2}$, which compares very well with the value $5.5 \times 10^{6} \mathrm{~Hz}^{2}$ obtained from a linear fit to the data in Fig. 2(b). Theoretically, $A_{h f}=\Sigma_{j}\left(1-3 \cos ^{2} \theta_{i j}\right) / r_{i j}{ }^{3}$, where the sum runs over all $V_{j}$ local moments around a given $L i$ nucleus $i$. The sum calculated over 32 unit cells yields $A_{h f}=0.174 / \AA^{3}=0.104 \mathrm{~mole} / \mathrm{cm}^{3}$, which is in reasonable agreement with the experimental value $A_{h f}=0.043 \mathrm{~mole} / \mathrm{cm}^{3}$ obtained from the linear fit to the data in Fig. 2(b).

The line shift $\mathrm{K}$ of the ${ }^{7} \mathrm{Li}$ NMR line varies linearly with $\chi_{M}$ as shown in Fig. 2(d). For a paramagnetic shift due to local moments, one has 


$$
\mathrm{K}=\mathrm{K}_{\mathrm{o}}+\overline{\mathrm{A}}_{\mathrm{hf}} \chi_{\mathrm{M}} \text {, }
$$

where $K_{0}$ is the Knight shift originating from the conduction electrons and $\bar{A}_{h f}$ is the hyperfine interaction between ${ }^{7} \mathrm{Li}$ nuclei and $\mathrm{V}$ paramagnetic ions. From a linear fit to the data in Fig. 2(d), one obtains $\mathrm{K}_{0}=0.001 \%$ and $\bar{A}_{h f}=0.144$ mole $/ \mathrm{cm}^{3}$. The value for $\mathrm{K}_{0}$ is very small, which is quite reasonable for ${ }^{7} \mathrm{Li}$ in view of the very small contact hyperfine interaction $\left(\mathrm{K}_{0}\right.$ of ${ }^{7} \mathrm{Li}$ in $\mathrm{Li}$ metal is only $0.026 \%$ ). Averaged over the powder distribution, $\bar{A}_{h f}$ should be zero for paramagnetic ions with isotropic $g$ factor. The value of $A_{h f}$ could be explained either as a dipolar interaction with local magnetic moments having an anisotropic $g$ factor or with a small transferred hyperfine interaction between $\mathrm{V} \mathrm{d}$-orbitals and $\mathrm{Li}$ nuclei.

The $T$ dependence of the nuclear spin-lattice relaxation rate $T_{1}{ }^{-1}$ for ${ }^{7} \mathrm{Li}$ in $\mathrm{LiV}_{2} \mathrm{O}_{4}$, shown in Fig. 2(e), indicates that the relaxation is dominated by the interaction with local paramagnetic moments. The contribution from the conduction electrons, estimated using the $\mathrm{K}_{\mathrm{o}}$ value above, is given by the Korringa relation $\left(T_{1} T\right)^{-1}=S^{-1} K_{o}{ }^{2}=5 \times 10^{-5} \mathrm{sec}^{-1} \mathrm{~K}^{-1}$ and is thus entirely negligible compared with the data in Fig. 2(e). For ${ }^{7} \mathrm{Li}$, the constant $\mathrm{S}=\left(\gamma_{\mathrm{e}} / \gamma_{\mathrm{n}}\right)^{2} \mathrm{~h} /\left(8 \pi^{2} \mathrm{k}_{\mathrm{B}}\right)=1.8 \times 10^{-6} \mathrm{sec}^{-1} \mathrm{~K}^{-1}$, where $\gamma_{e}$ is the electronic gyromagnetic ratio and $h$ is Planck's constant. The contribution to $T_{1}{ }^{-1}$ due to paramagnetic ions is $\left(T_{1} T\right)^{-1}=\gamma_{n}{ }^{2} \bar{A}_{h f^{2}} k_{B} \Sigma_{q} \operatorname{Im} \chi^{ \pm}\left(q, \omega_{L}\right) / \omega_{L}$, where $q$ is the wavevector and $\omega_{\mathrm{L}}=2 \pi \gamma_{\mathrm{n}} \mathrm{H}$ is the Larmor angular frequency. In the limit of high $T$ where correlations among paramagnetic ions are negligible, this reduces to

$$
\frac{1}{T_{1} T}=\frac{\gamma_{n}^{2} \bar{A}_{h f^{2} N_{A} k_{B} \chi_{M}}}{\omega_{e}}
$$

where the exchange frequency $\omega_{e}$ is given by $\omega_{e}^{2}=\left(8 \pi^{2} / 3\right) J^{2} z S(S+1) h^{2}$ and $z$ is the number of nearest neighbor $\mathrm{V}$ ions to $\mathrm{V} V$ ion. The $A F \mathrm{~V}-\mathrm{V}$ exchange interaction constant is $\mathrm{J}=3 \mathrm{k}_{B} \theta /[2 \mathrm{zS}(\mathrm{S}+1)]=-11.6 \mathrm{~K}$, using $\mathrm{z}=6, \mathrm{~S}=1 / 2$ and Weiss temperature $\theta=-35 \mathrm{~K}$ from above, yielding $\omega_{e}=5 \times 10^{12} \mathrm{rad} / \mathrm{sec}$. Inserting this $\omega_{e}$ and the above $\bar{A}_{h f}$ into Eq. (3) yields $\left(\mathrm{T}_{1} \mathrm{~T}\right)^{-1}=35 \chi_{\mathrm{M}}\left(\mathrm{sec}^{-1} \mathrm{~K}^{-1}\right)$. As shown in Fig. 2(f), this prediction, represented by the dashed line, gives good agreement with the data in the limit of high $\mathrm{T}$ where one expects weak correlation among the localized $\mathrm{V}$ moments. The much stronger relaxation observed in Figs. 2(e,f) at low $T$ must arise from AF fluctuations at a wavevector $q=q_{A F}$ not included in Eq. (3) which involves only the $q=0$ uniform susceptibility, $\chi_{M}$, and is thus only correct as long as all $q$-components of the susceptibility are equal to the $q=0$ uniform one. It should be noted that a critical behavior $\left(T_{1} T\right)^{-1} \alpha\left(T-T_{N}\right)^{-n}$ expected for a divergent staggered susceptibility does not fit the experimental data in Fig. 2(e) for any reasonable choice of parameters. On the other hand a good fit to the data in Fig. 2(f) is obtained with an empirical quadratic dependence: $\left(T_{1} T\right)^{-1}=6600 \chi_{\mathrm{M}^{2}}\left(\mathrm{sec}^{-1} \mathrm{~K}^{-1}\right)$, as shown by the solid curve in the figure. The implications of this behavior, which is not borne out in any theory of critical slowing down of spin fluctuations, are not understood.

We have thus established that the $\mathrm{V}$ ions in metallic $\mathrm{LiV}_{2} \mathrm{O}_{4}$ do indeed carry a local magnetic moment and that these moments are antiferromagnetically coupled. These moments evidently have spin $S=1 / 2$. Electron correlations are manifested not only in the existence of the local V moments but also in the occurrence of AF spin fluctuations which strongly affect the Li nuclei spin-lattice relaxation rate below $\sim 150 \mathrm{~K}$. On the other hand, the effective moment $/ \mathrm{V}$ ion from the $\chi(\mathrm{T})$ measurements is about $15 \%$ larger than that expected for $g=2$ and $S=1 / 2$. This implies that the $\mathrm{V}$ spins have a ferromagnetic coupling to the conduction electron 
spins which would increase the $\mathrm{g}$ value of the $\mathrm{V}$ ions beyond $\mathrm{g}=2$. Further experiments are necessary to clarify this issue.

Our results are consistent with those of ultraviolet (UPS) and X-ray (XPS) photoemission spectroscopy measurements on $\mathrm{LiV}_{2} \mathrm{O}_{4}$ which indicated that $\mathrm{D}\left(\mathrm{E}_{\mathrm{F}}\right)$ is much lower than predicted from band structure calculations (for $\mathrm{LiTi}_{2} \mathrm{O}_{4}$ ) [16]. This observation is indicative of electron correlation effects and the failure of the (weakly correlated electron) band picture. The authors analyzed their data in terms of a localized picture in which the $V$ ion fluctuates between the $d^{1}$ and $d^{2}$ configurations on a time scale longer than that of photoemission $\left(-10^{-15} \mathrm{sec}\right)$. From analysis of their data, the authors obtained a value for the intra-atomic Coulomb energy $\mathrm{U} \sim 2 \mathrm{eV}$, which is on the same order as that previously estimated for $\mathrm{VO}_{2}$ and $\mathrm{V}_{2} \mathrm{O}_{3}$. The authors suggested that the long-range Coulomb interaction could also be important to the suppression of $D\left(E_{F}\right)$.

\section{The Metal-Insulator Transition in $\mathrm{Sr}_{1 \cdot \mathrm{x}} \mathrm{La}_{\mathrm{x}} \mathrm{VO}_{3}$}

The $\mathrm{Sr}_{1-\mathrm{x}} \mathrm{La}_{\mathrm{x}} \mathrm{VO}_{3}(0 \leq \mathrm{x} \leq 1)$ system, with the three-dimensional perovskite structure or a distorted variant thereof, was first investigated more than 30 years ago [14] and is currently still of interest because of its striking similarities to the cuprate high $\mathrm{T}_{\mathrm{c}}$ superconductors. The end-member $\mathrm{SrVO}_{3}$ is a metallic Pauli paramagnet $[17,18]$ whereas the other one, $\mathrm{LaVO}_{3}$, is an antiferromagnetic insulator with $T_{N} \approx 140 \mathrm{~K}$ [19]. A composition-induced metal-to-insulator (M-I) transition occurs with increasing $x$ at $x \approx 0.8$ [20]. These features are similar to those of the cuprates noted in Section 1. For example, in the $\mathrm{La}_{2-x} \mathrm{Sr}_{x} \mathrm{CuO}_{4}$ system [9], the $\mathrm{x}=0$ member is an $\mathrm{AF}$ insulator with $\mathrm{T}_{\mathrm{N}}=325 \mathrm{~K}$. The system becomes metallic and superconducting for $0.1 \leq x \leq 0.25$. Upon increasing $x$ further, the system is not superconducting and behaves more like a normal d-band metal. Thus the change in composition from $\mathrm{La}_{2} \mathrm{CuO}_{4}$ to the heavily $\mathrm{Sr}$-doped non-superconducting metallic phase apparently spans the theoretically difficult region from the limit of strong correlation (i.e., local moments) to the limit corresponding to conventional band theory. We carried out combined crystallographic, $\chi(T)$ and ${ }^{51} \mathrm{~V}$ NMR measurements on the $\mathrm{Sr}_{1-x} \mathrm{La}_{\mathrm{x}} \mathrm{VO}_{3}$ $(0.1 \leq x \leq 1)$ system, to clarify the importance of electron correlations in the metallic phase and to the M-I transition [21]. A complete solid solution was found to form between $x=0$ and 1 , in agreement with [22]. Also in agreement with previous work [20], our resistivity versus temperature measurements indicated the M-I transition to occur at $\mathrm{x} \approx 0.8$.

The T-dependent molar susceptibility $\chi_{M}(\mathrm{~T})$ of $\mathrm{Sr}_{1-\mathrm{x}} \mathrm{La}_{\mathrm{x}} \mathrm{VO}_{3}$ is plotted for different compositions $x$ in Fig. 3(a). The onset of long-range AF order is evident for $x=0.9$ and 1.0 via kinks in the data at $T_{N} \approx 105 \mathrm{~K}$ and $140 \mathrm{~K}$, respectively. From this figure, $\chi_{M}(T)$ is seen to be nearly independent of $T$, even for the $A F$ compositions $\mathrm{x}>0.8$ for $\mathrm{T}>\mathrm{T}_{\mathrm{N}}$, except for a small low-T Curie-like upturn presumably due to paramagnetic impurities. The susceptibility at $300 \mathrm{~K}$ corrected for the Curie term, $\chi_{M}{ }^{\text {corr }}(300 \mathrm{~K})$, is plotted versus $x$ in Fig. 3(b). A smooth variation in $\chi_{M}{ }^{\operatorname{cor}}(300 \mathrm{~K})$ with $\mathrm{x}$ is seen across the whole composition range, with no obvious discontinuity near $\mathrm{x}=0.8$ at which the $\mathrm{M}-\mathrm{I}$ transition occurs, akin to the behavior seen across the $\mathrm{M}-\mathrm{I}$ transition in the $\mathrm{La}_{2-\mathrm{x}} \mathrm{Sr}_{\mathrm{x}} \mathrm{CuO}_{4}$ system [9].

From the ${ }^{51} \mathrm{~V}$ NMR measurements, the Knight shift $K_{0}$ was found to be independent of both temperature and composition in the metallic phase with $x \leq 0.7$. The former result is expected for a metal, but the latter is anomalous. For typical metals, one expects $K_{0}$ to scale with $\chi_{M}$ in Fig. 3(b), which clearly does not occur. The variation of the ${ }^{51} \mathrm{~V}$ spin-lattice relaxation rate $T_{1}{ }^{-1}$ with $T$ in the metallic phase is shown in Fig. 4, where the Korringa relation $T_{1} T=$ constant, independent of $x$, is found to hold within the error limits. Thus the Knight shift and spin-lattice 
relaxation rate measurements are consistent with each other according to the Korringa relation, and show no evidence of spin correlations in the metallic phase such as observed above for $\mathrm{LiV}_{2} \mathrm{O}_{4}$ and cited above for the metallic side of the $\mathrm{M}-\mathrm{I}$ transition in $\mathrm{La}_{2-\mathrm{x}} \mathrm{Sr}_{\mathbf{x}} \mathrm{CuO}_{4}$.

To understand why $K_{0}(x)$ and $\left(T_{1} T\right)^{-1}(x)$ are independent of $x$ in the metallic phase of $\mathrm{Sr}_{1-\mathrm{x}} \mathrm{La}_{\mathrm{x}} \mathrm{VO}_{3}$ in contrast to the strong composition dependence of $\chi_{M}(x)$, detailed combined analysis of these three measurements were carried out which reconciled these results [21]. With increasing $x$, the $d$-band band structure density of states was found to be nearly independent of $x$, whereas the ferromagnetic Stoner exchange enhancement factor increases strongly with $x$, resulting in the observed composition dependence of $\chi$ and composition independence of $K_{0}$ and $\left(T_{1} T\right)^{-1}$.

\section{4d- and 5d-Transition Metal Oxides with the $\mathrm{K}_{2} \mathrm{NiF}_{4}$ Structure}

As noted in Section 1, the parent compounds of the high $T_{c}$ cuprate superconductors are two-dimensional spin $1 / 2$ Heisenberg antiferromagnets on a square lattice, and short-range AF order persists in the superconducting compositions. In order to deepen our understanding of the magnetic properties of these cuprates, and to expand the range of materials which might exhibit high $T_{c}$ superconductivity, we are investigating the structural and magnetic properties of transition metal oxides which would be expected to have similar magnetic properties. Here we discuss our work on the $5 \mathrm{~d}$ oxide $\mathrm{Sr}_{2} \mathrm{IrO}_{4}[23,24]$ and the $4 \mathrm{~d}$ oxide $\mathrm{Sr}_{2} \mathrm{RhO}_{4}$ [24] which crystallize in the $\mathrm{K}_{2} \mathrm{NiF}_{4}$ structure $[25,26]$.

The electronic configurations of the $\mathrm{Ir}^{+4}$ and $\mathrm{Rh}^{+4}$ ions are $[\mathrm{Xe}] 4 \mathrm{f}^{14} 5 \mathrm{~d}^{5}$ and $[\mathrm{Kr}] 4 \mathrm{~d}^{5}$, respectively. From the large crystalline electric fields at the d-ion site and the large spin-orbit couplings, we expect the $\mathrm{Ir}$ and $\mathrm{Rh}$ ions in $\mathrm{Sr}_{2} \mathrm{IrO}_{4}$ and $\mathrm{Sr}_{2} \mathrm{RhO}_{4}$ to be in the low-spin configuration $t_{2 g}{ }^{5}$, with the ground state being ${ }^{2} \mathrm{~T}_{2}$. This state is split by spin-orbit coupling and the tetragonal crystal field into three Kramers doublets. Thus, the ground states of $\mathrm{Sr}_{2} \mathrm{IrO}_{4}$ and $\mathrm{Sr}_{2} \mathrm{RhO}_{4}$ are expected to be spin $1 / 2$ Kramers doublets, where the unpaired spin occupies a half-filled $d_{x y}$ orbital, similar to $\mathrm{La}_{2} \mathrm{CuO}_{4}$ where the $\mathrm{Cu}^{+2}$ hole spin resides in a half-filled $e_{\mathrm{g}}\left(\mathrm{d}_{\mathrm{x}}{ }^{2}-\mathrm{y}^{2}\right)$ orbital.

Samples of $\mathrm{Sr}_{2} \mathrm{IrO}_{4}$ and $\mathrm{Sr}_{2} \mathrm{RhO}_{4}$ were prepared using standard solid state synthesis techniques. Neutron and high-resolution synchrotron $\mathrm{x}$-ray powder diffraction data were obtained at Oak Ridge National Laboratory and Brookhaven National Laboratory, respectively. Magnetization measurements were made with a Quantum Design SQUID magnetometer and an Oxford Instruments Faraday magnetometer. Electrical resistivity measurements indicate that $\mathrm{Sr}_{2} \mathrm{IrO}_{4}$ is an insulator [23], while $\mathrm{S}_{2} \mathrm{RhO}_{4}$ showed metallic behavior below $150 \mathrm{~K}$ [26].

The diffraction data for $\mathrm{Sr}_{2} \mathrm{IrO}_{4}$ and $\mathrm{Sr}_{2} \mathrm{RhO}_{4}$ showed the presence of superstructure reflections which could be indexed on a unit cell of dimensions $2^{1 / 2} \mathrm{a} \times 2 \mathrm{c}$, where $\mathrm{a}$ and $\mathrm{c}$ are the tetragonal lattice parameters for the $\mathrm{K}_{2} \mathrm{NiF}_{4}$-type $\mathrm{I} / \mathrm{mmm}$ cell $[23,24]$. A structure was proposed [23,24], shown in Fig. 5, in which the $\mathrm{IrO}_{6}$ and $\mathrm{RhO}_{6}$ octahedra are rotated about the crystallographic $\mathrm{c}$ axis by about $11^{\circ}$ and $9.7^{\circ}$, respectively, thereby reducing the space group symmetry from $\mathrm{I} 4 / \mathrm{mmm}$ to $\mathrm{I} 4_{1} / \mathrm{acd}$, similar to the structural distortion observed in $\mathrm{K}_{2} \mathrm{NiF}_{4}$-type $\mathrm{Ca}_{2} \mathrm{MnO}_{4}$ [27]. This distortion contrasts with that found below $530 \mathrm{~K}$ in $\mathrm{La}_{2} \mathrm{CuO}_{4}$, in which the $\mathrm{CuO}_{6}$ octahedra are rotated in a staggered fashion about the (110) tetragonal axis in the a-b plane.

The $\chi(\mathrm{T})$ for $\mathrm{Sr}_{2} \mathrm{IrO}_{4}$ is shown in Fig. 6(a) [23]. Below $\mathrm{T}_{\mathrm{N}} \approx 250 \mathrm{~K}$, the susceptibility increases dramatically. Measurements of magnetization vs. field isotherms revealed that a small ferromagnetic (FM) magnetization developed below $T_{N}$ as shown in Fig. $6($ b) for data taken at $5 \mathrm{~K}$. The magnitude of the remanent 
saturation magnetization in Fig. $6(b)$ is $M_{s} \approx 0.30 \mathrm{G} \mathrm{cm}^{3} / \mathrm{g}=0.023 \mu_{\mathrm{B}} / \mathrm{Ir}$ atom. This $M_{S}$ is much smaller than the ordered moment $\left\langle\mu>=g S \mu_{B} \approx 1 \mu_{B}\right.$ expected for $F M$ alignment of an atom with spin $1 / 2$ and $g \approx 2$. Furthermore, by analogy to the layered cuprate parent compounds with similar structures, one expects $\mathrm{AF}$ rather than FM order. Single crystal magnetization measurements indicate that the FM moment is aligned in the c-direction [24]. We conclude that the magnetic ordering below $\mathrm{T}_{\mathrm{N}}$ in $\mathrm{Sr}_{2} \mathrm{IrO}_{4}$ is most likely weak ferromagnetism in which the basic AF magnetic structure is slightly canted parallel to the c-axis. This canting presumably arises from the Dzyaloshinsky-Moriya exchange interaction between the Ir ions which is allowed in the distorted structure.

In contrast, weak ferromagnetism is not seen in $\mathrm{Sr}_{2} \mathrm{RhO}_{4}$, despite the fact that the structures are similar. However, $\chi(\mathrm{T})$ data do show a broak peak at $\approx 200 \mathrm{~K}$, possibly indicating the presence of $2 \mathrm{D}$ short range $\mathrm{AF}$ order [26]. Fluorine substituted phases of the type $\mathrm{Sr}_{2} \mathrm{RhO}_{4-\mathrm{x}} \mathrm{F}_{\mathrm{x}}$ were also synthesized for $0 \leq \mathrm{x} \leq 0.15$ [24]. These compounds showed metallic behavior and weak ferromagnetism at low $\mathrm{T}$.

Unlike $\mathrm{Sr}_{2} \mathrm{IrO}_{4}$, the $\mathrm{K}_{2} \mathrm{NiF}_{4}$-type compound $\mathrm{Sr}_{2} \mathrm{RuO}_{4}$ is a good metal (at least parallel to the a-b plane) [28] showing (nearly) temperature independent Pauli paramagnetism $[29,30]$. The electronic configuration of $R^{+4}$ is $[K r] 4 d^{4}$. A crystallographic, resistivity and magnetic susceptibility study was recently reported for the solid solution $\mathrm{Sr}_{2} \mathrm{Ir}_{1-x} \mathrm{Ru}_{\mathrm{x}} \mathrm{O}_{4}$ which was found to show an insulator-to-metal transition with increasing $x$ at $x \approx 0.7$ [30]. The lattice parameters versus composition show distinct changes in slope upon traversing the insulator-to-metal transition. In the insulating compositions, the $\mathrm{Ru}$ ion was found to have spin $\mathrm{S}=1$ (assuming $\mathrm{g} \approx 2$ ), but the Ru local moment is apparently progressively destroyed in the metallic phase as $x$ increases above $x \approx 0.7$.

\section{Concluding Remarks}

Among the compounds discussed here, electron correlation effects have been found to be particularly important in the metallic compounds $\mathrm{LiV}_{2} \mathrm{O}_{4}$ and possibly $\mathrm{Sr}_{2} \mathrm{Ir}_{1-\mathrm{x}} \mathrm{Ru}_{\mathrm{x}} \mathrm{O}_{4}(\mathrm{x}>0.7)$, but not in metallic $\mathrm{Sr}_{1-\mathrm{x}} \mathrm{La}_{\mathrm{x}} \mathrm{VO}_{3}(\mathrm{x}<0.7)$, and they cause the compounds $\mathrm{Sr}_{2} \mathrm{IrO}_{4}$ and $\mathrm{ZnV}_{2} \mathrm{O}_{4}$ to be (Mott-Hubbard) insulators. The $\mathrm{LiV}_{2} \mathrm{O}_{4}$ spinel compound is especially interesting, because the $\mathrm{V}$ ions exhibit rather clear local moment $(S=1 / 2)$ behavior even though the compound is a metal. Our ${ }^{7} \mathrm{Li}$ NMR experiments indicate that antiferromagnetic spin correlations occur between the $\mathrm{V}$ ions, consistent with the negative sign of the Weiss temperature from magnetic susceptibility measurements.

The local moment behavior of the $\mathrm{V}$ ions and the $\mathrm{AF}$ correlations between them are qualitatively the same in $\mathrm{LiV}_{2} \mathrm{O}_{4}$ as those of the $\mathrm{Cu}^{+2}$ ions $(\mathrm{S}=1 / 2)$ in the cuprate high temperature superconductors, yet $\mathrm{LiV}_{2} \mathrm{O}_{4}$ is not superconducting above $1.5 \mathrm{~K}$. However, at least three characteristics of the cuprates are lacking. First, the $\mathrm{V}$ ions have a three-dimensional structure in contrast to the square lattice layered structure of the $\mathrm{Cu}$ ions. Second, the exchange coupling between the $\mathrm{V}$ ions $(\mathrm{I}) \approx$ $12 \mathrm{~K})$ is more than 100 times weaker than between the $\mathrm{Cu}$ ions $(1500 \mathrm{~K})$. Third, the oxygen $2 p$ orbitals are $\approx 2 \mathrm{eV}$ below the Fermi energy $E_{\mathrm{F}}$ in $\mathrm{LiV}_{2} \mathrm{O}_{4}[5]$, whereas they overlap $\mathrm{E}_{\mathrm{F}}$ in the cuprates; i.e., electronic conduction occurs at least in large measure on the oxygen sublattice of the cuprates. Future work will hopefully determine whether one or more of these features are crucial to high temperature superconductivity. 


\section{Acknowledgments}

We are grateful to J. E. Ostenson for SQUID magnetometer measurements of $\mathrm{LiV}_{2} \mathrm{O}_{4}$. Ames Laboratory is operated for the U.S. Department of Energy by Iowa State University under Contract No. W-7405-Eng-82. The work at Ames was supported by the Director for Energy Research, Office of Basic Energy Sciences. The work at the National Synchrotron Light Source, Brookhaven National Laboratory was supported by the U.S. Department of Energy, Division of Materials Sciences, and Division of Chemical Sciences. The work at Oak Ridge National Laboratory was supported by the Division of Materials Sciences, U.S. Department of Energy, under Contract No. DE-AC05-84-OR21400 with Martin Marietta Energy Systems, Inc.

\section{References}

*Permanent address: Sony Research Center, 174, Fujitsuka-cho, Hodogaya-ku, Yokohama, 240 Japan

+Present address: Solid State Physics Group, Tata Institute of Fundamental Research, Homi Bhabha Road, Bombay 400005, India

1. J. G. Bednorz and K. A. Müller, Z. Phys. B 64, 189 (1986); J. G. Bednorz, M. Takashige, and K. A. Müller, Mater. Res. Bull. 22, 819 (1987).

2. A. W. Sleight, J. L. Gillson, and P. E. Bierstedt, Solid State Commun. 17, 27 (1975).

3. D. C. Johnston, Ph.D. Thesis, University of California, San Diego (1975), and references cited, unpublished; D. C. Johnston, H. Prakash, W. H. Zachariasen, and R. Viswanathan, Mater. Res. Bull. 8, 777 (1973); D. C. Johnston, J. Low Temp. Phys. 25, 145 (1975).

4. R. W. McCallum, D. C. Johnston, C. A. Luengo, and M. B. Maple, J. Low Temp. Phys. 25, 177 (1976); R. N. Shelton, D. C. Johnston, and H. Adrian, Solid State Commun. 20, 1077 (1976).

5. S. Satpahy and R. M. Martin, Phys. Rev. B 36, 7269 (1987); S. Massidda, J. Yu, and A. J. Freeman, ibid. 38, 11352 (1988).

6. J. F. Schooley, W. R. Hosler, and M. L. Cohen, Phys. Rev. Lett. 12, 474 (1964).

7. L. Gao, Y. Y. Xue, F. Chen, Q. Xiong, R. L. Meng, D. Ramirez, C. W. Chu, J. H. Eggert, and H. K. Mao, Phys. Rev. B 50, 4260 (1994).

8. Chemistry of Superconductor Materials, edited by T. A. Vanderah (Noyes, Park Ridge, NJ, 1992).

9. For a review, see D. C. Johnston, J. Magn. Magn. Mater. 100, 218 (1991).

10. For a review, see R. J. Birgeneau and G. Shirane, in Physical Properties of High Temperature Superconductors I, edited by D. M. Ginsberg (World Scientific, Singapore, 1989), pp. 151-211.

11. D. B. Rogers, J. L. Gillson, and T. E. Gier, Solid State Commun. 5, 263 (1967).

12. H. Kessler and M. J. Sienko, J. Chem. Phys. 55, 5414 (1971); B. L. Chamberland and T. A. Hewston, Solid State Commun. 10, 693 (1986).

13. K. Kawakami, Y. Sakai, and N. Tsuda, J. Phys. Soc. Jpn. 55, 3174 (1986), and references cited.

14. S. Niziol, Phys. Stat. Sol. (a) 18, K11 (1973), and references cited.

15. K. H. Kim, F. Borsa, A. V. Mahajan, D. R. Torgeson, and D. C. Johnston, unpublished.

16. A. Fujimori, K. Kawakami, and N. Tsuda, Phys. Rev. B 38, 7889 (1988).

17. B. Reuter and M. Wollnik, Naturwiss. 50, 569 (1963). 
18. B. L. Chamberland and P. S. Danielson, J. Solid State Chem. 3, 243 (1971); P. Dougier, J. C. C. Fan, and J. B. Goodenough, ibid. 14, 247 (1975).

19. V. G. Zubkov, G. V. Bazuev, V. A. Perelyaev and G. P. Shveiken, Fiz. Tverd. Tela (Leningrad) 15, 1610 (1973) [Sov. Phys. Solid State 15, 1078 (1973)]; P. Dougier and P. Hagenmuller, J. Solid State Chem. 15, 158 (1975).

20. P. Dougier and A. Casalot, J. Solid State Chem. 2, 396 (1970).

21. A. V. Mahajan, D. C. Johnston, D. R. Torgeson, and F. Borsa, Phys. Rev. B 46, 10973 (1992); 46, 10966 (1992).

22. T. Shin-ike, T. Sakai, G. Adachi, and J. Shiokawa, Mater. Res. Bull. 11, 249 (1976).

23. M. K. Crawford, M. A. Subramanian, R. L. Harlow, J. A. Fernandez-Baca, Z. R. Wang, and D. C. Johnston, Phys. Rev. B 49, 9198 (1994).

24. M. A. Subramanian, M. K. Crawford, R. L. Harlow, T. Ami, J. A. FernandezBaca, Z. R. Wang, and D. C. Johnston, in Proc. Fourth Int. Conf. on Materials and Mechanisms of Superconductivity and High Temperature Superconductors, Grenoble, France, 4-9 July 1994, Physica C (to be published).

25. J. J. Randall, Jr., L. Katz, and R. Ward, J. Am. Chem. Soc. 79, 266 (1957); J. J. Randall and R. Ward, ibid. 81, 2629 (1959).

26. T. Shimura, M. Itoh, Y. Inaguma, and T. Nakamura, Phys. Rev. B 49, 5591 (1994), and references cited.

27. M. E. Leonowicz, K. R. Poeppelmeier, and J. M. Longo, J. Solid State Chem. 59, 71 (1985); J. Takahashi and N. Kamegashira, Mater. Res. Bull. 28, 565 (1993).

28. F. Lichtenberg, A. Catana, J. Mannhart, and D. G. Schlom, Appl. Phys. Lett. 60, 1138 (1992).

29. W. D. Komer and D. J. Machin, J. Less-Common Met. 61, 91 (1978).

30. R. J. Cava, B. Batlogg, K. Kiyono, H. Takagi, J. J. Krajewski, W. F. Peck, Jr., L. W. Rupp, Jr., and C. H. Chen, Phys. Rev. B 49, 11890 (1994). 


\section{Figure Captions}

Fig. 1. Inverse molar magnetic susceptibility $\chi_{M}{ }^{-1}$ versus temperature $T$ for $\mathrm{LiV}_{2} \mathrm{O}_{4}$. The solid line is a linear least square fit to the data (Curie-Weiss law) [15].

Fig. 2. ${ }^{7} \mathrm{Li}$ NMR line width at half maximum measured at $17 \mathrm{MHz}(\Delta v)$, paramagnetic line shift measured at $17 \mathrm{MHz}$ and $135 \mathrm{MHz}$, and nuclear spin-lattice relaxation rate $T_{1}{ }^{-1}$ divided by $T,\left(T_{1} T\right)^{-1}$, versus temperature $T[(a),(c),(e)]$ and versus molar susceptibility $\chi_{M}\left[(b),(d)\right.$, (f)], respectively, for $\mathrm{LiV}_{2} \mathrm{O}_{4}$. In (b), the solid curve is a fit of Eq. (1) to the data. In (d), the solid line is a fit of Eq. (2) to the data. In ( $f$ ), the dashed line is the calculated dependence at high $T$ in Eq. (3), and the solid curve is an empirical fit $\left(\mathrm{T}_{1} \mathrm{~T}\right)^{-1}=6600 \chi_{\mathrm{M}^{2}}\left(\mathrm{sec}^{-1} \mathrm{~K}^{-1}\right)$ [15].

Fig. 3. (a) Molar magnetic susceptibility $\chi_{M}$ for $\mathrm{Sr}_{1-\mathrm{x}} \mathrm{La}_{\mathbf{x}} \mathrm{VO}_{3}$ versus temperature $T$ for different La contents $\mathrm{x}$; (b) Molar magnetic susceptibility corrected for small Curie-Weiss impurity terms, $\chi_{M}{ }^{\text {corr, }}$, versus La content $x$ at $300 \mathrm{~K}$ [21].

Fig. 4. ${ }^{51} \mathrm{~V}$ nuclear spin-lattice relaxation rate $1 / \mathrm{T}_{1}$ versus temperature $\mathrm{T}$ for metallic samples of $\mathrm{Sr}_{1-\mathrm{x}} \mathrm{La}_{\mathrm{x}} \mathrm{VO}_{3}$ with $\mathrm{x} \leq 0.6$ [21].

Fig. 5. Structure of $\mathrm{Sr}_{2} \mathrm{IrO}_{4}$ (I4 $1 /$ acd) showing the $\mathrm{IrO}_{6}$ octahedra rotation pattern in each layer of height $z$ along the $c$-axis of the unit cell. The square superimposed on each figure is the unit cell in the $a-b$ plane. The $c$ axis is perpendicular to the page [23].

Fig. 6. (a) Molar magnetic susceptibility versus temperature $T$ and (b) magnetization versus applied magnetic field hysteresis loop at $5 \mathrm{~K}$, for $\mathrm{Sr}_{2} \mathrm{IrO}_{4}$ [23]. 


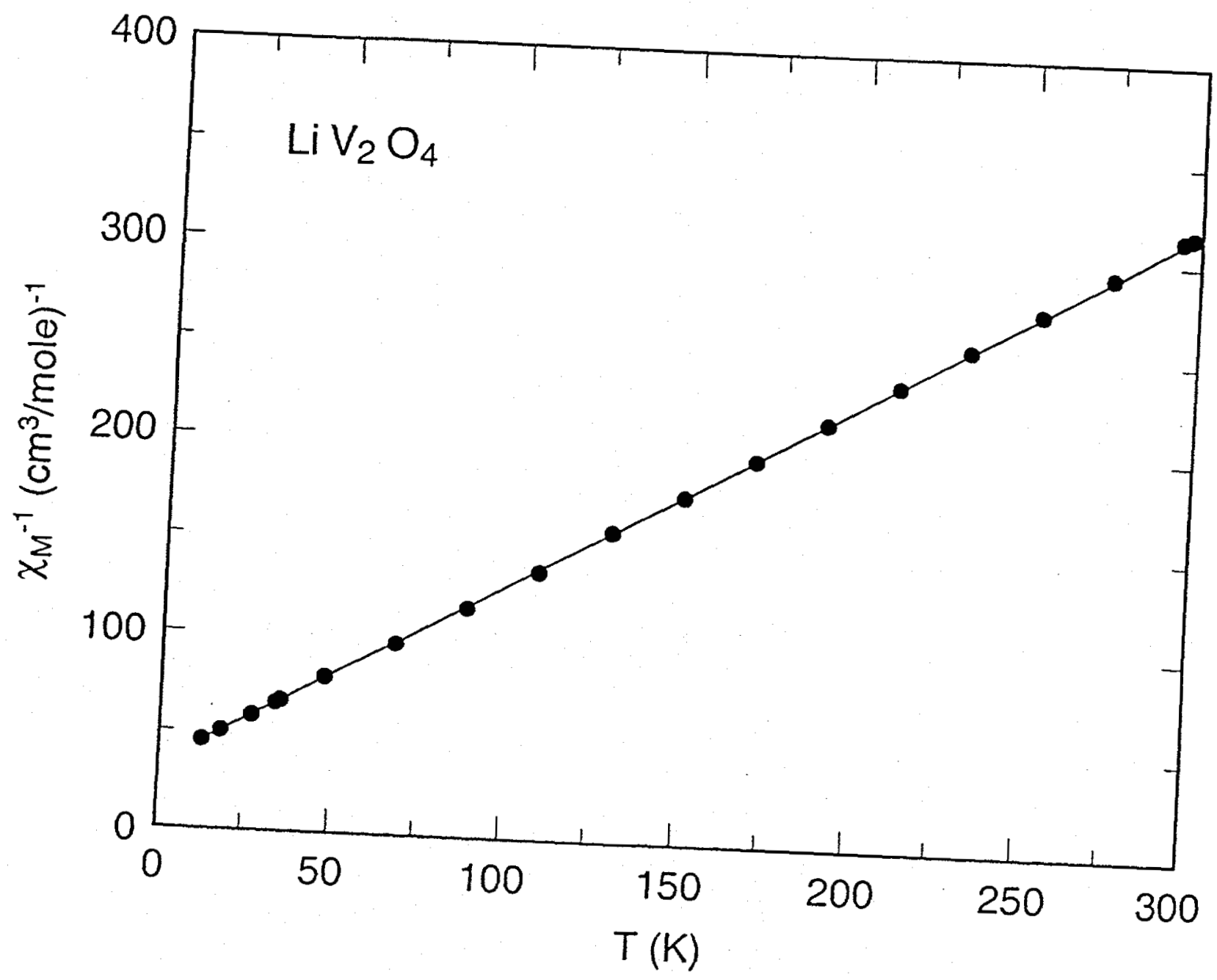

Figure 1

\section{DISCLAIMER}

This report was prepared as an account of work sponsored by an agency of the United States Government. Neither the United States Government nor any agency thereof, nor any of their employees, makes any warranty, express or implied, or assumes any legal liability or responsibility for the accuracy, completeness, or usefulness of any information, apparatus, product, or process disclosed, or represents that its use would not infringe privately owned rights. Reference herein to any specific commercial product, process, or service by trade name, trademark, manufacturer, or otherwise does not necessarily constitute or imply its endorsement, recommendation, or favoring by the United States Government or any agency thereof. The views and opinions of authors expressed herein do not necessarily state or reflect those of the United States Government or any agency thereof. 


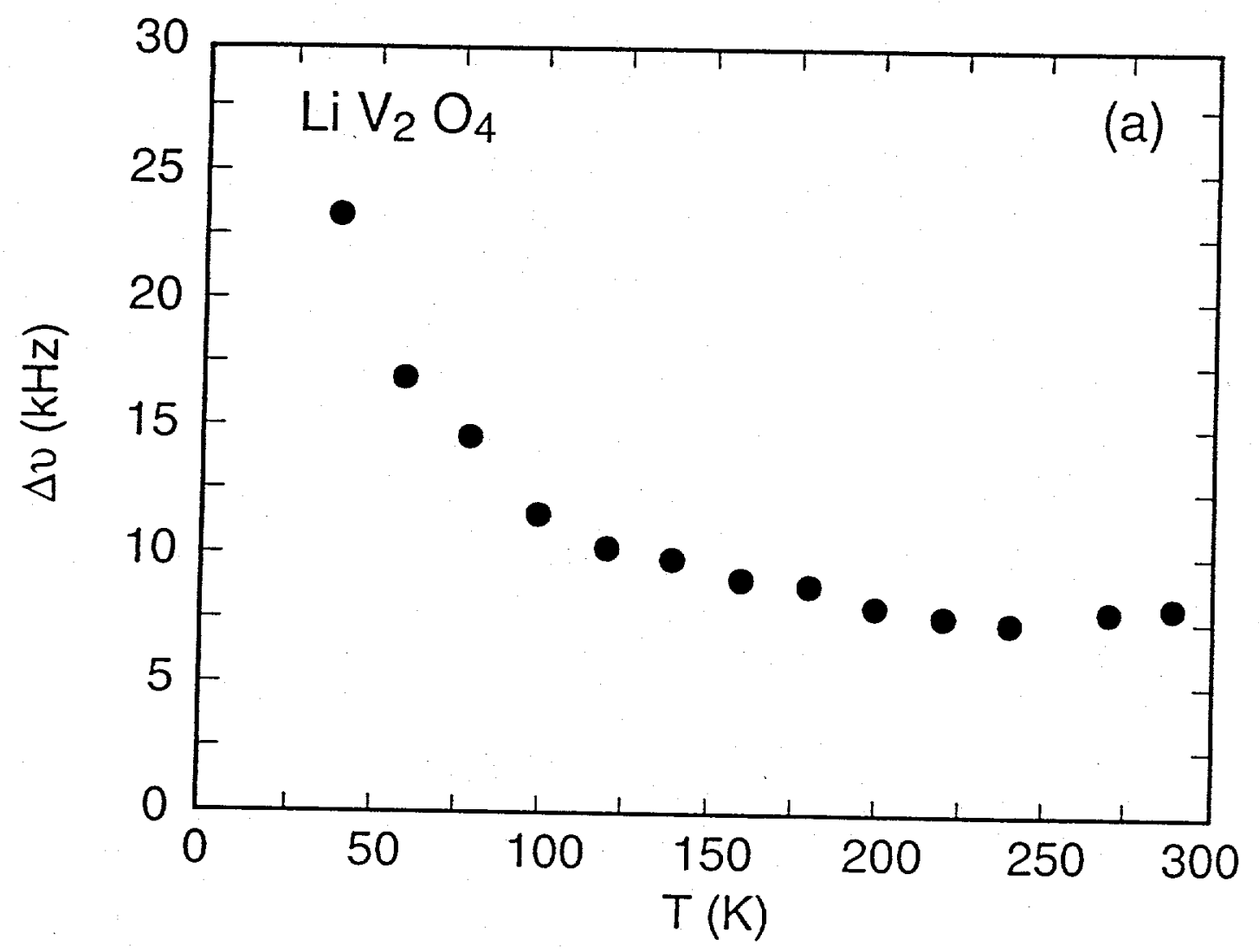

Figure $2(a)$ 


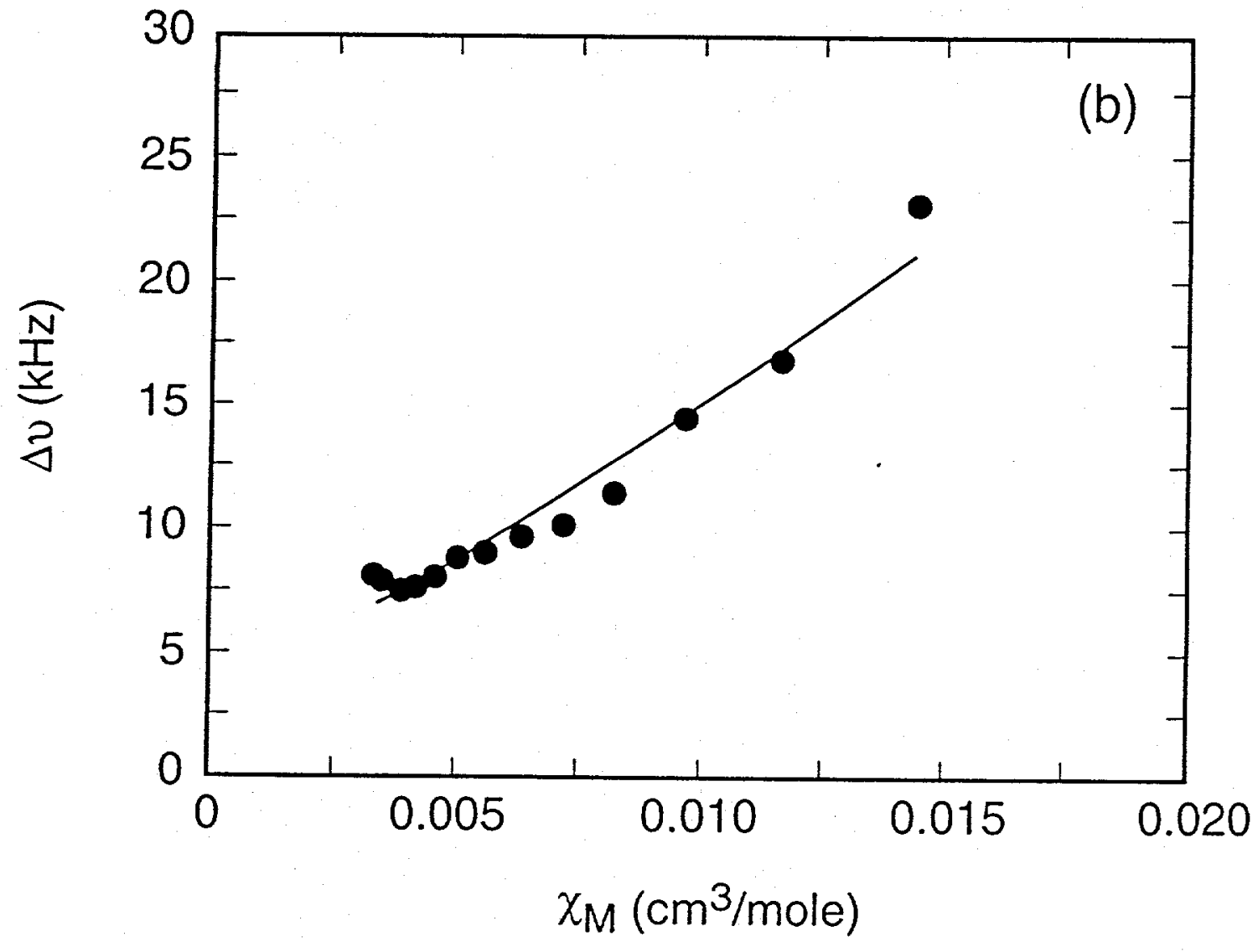

Figure 2(b) 


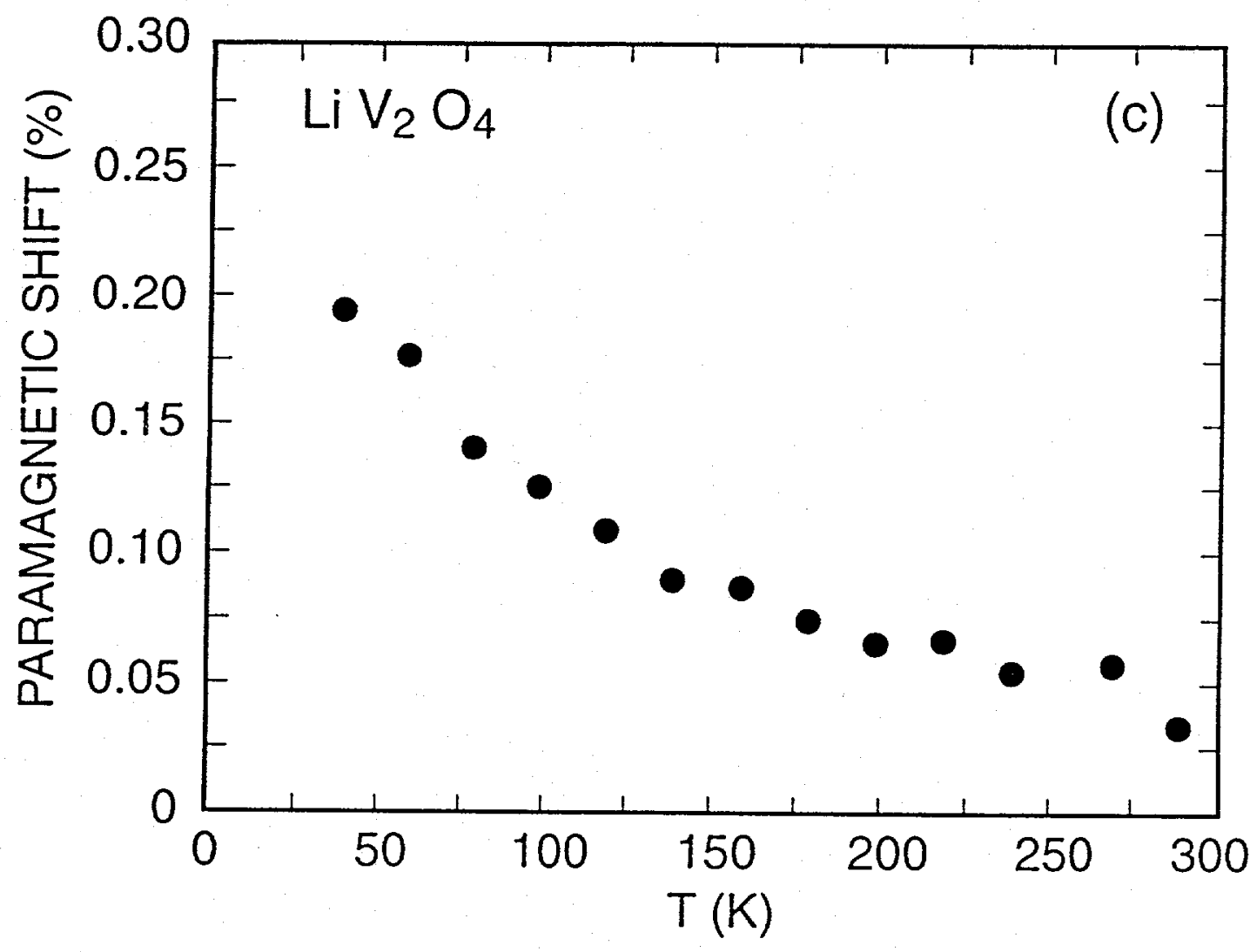

Figure $2(-c)$ 


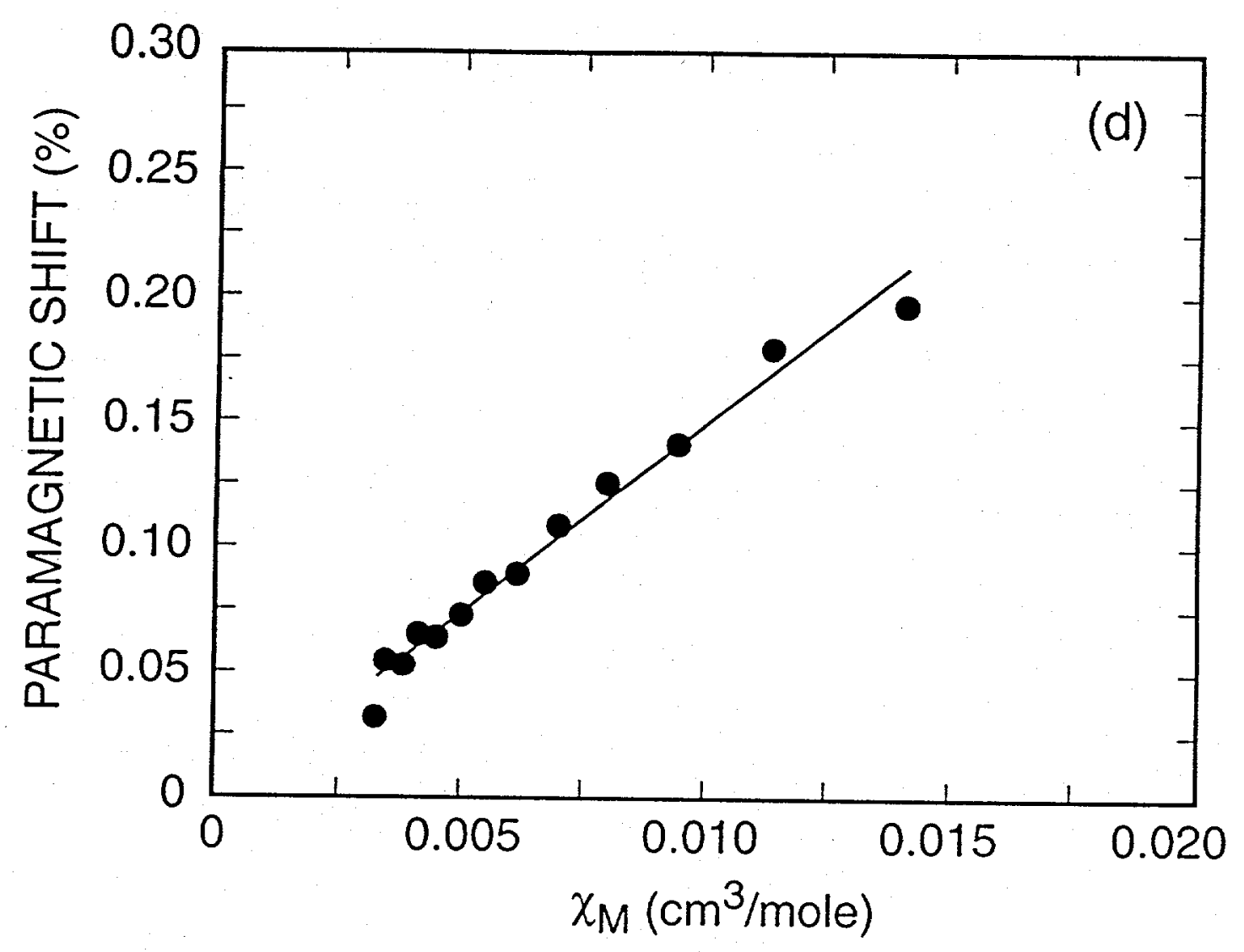

Figure 2(d) 


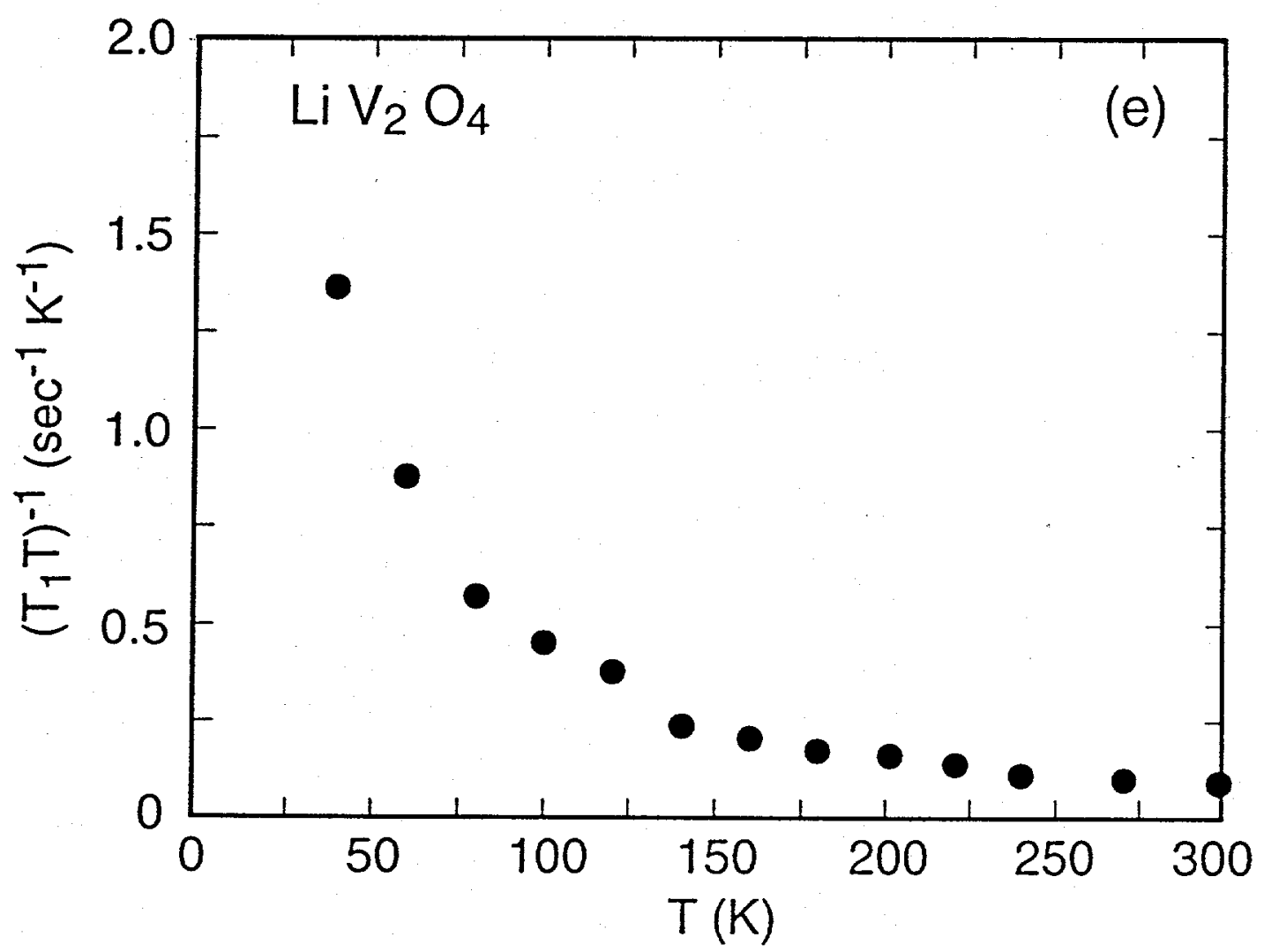

Figure 2(e) 


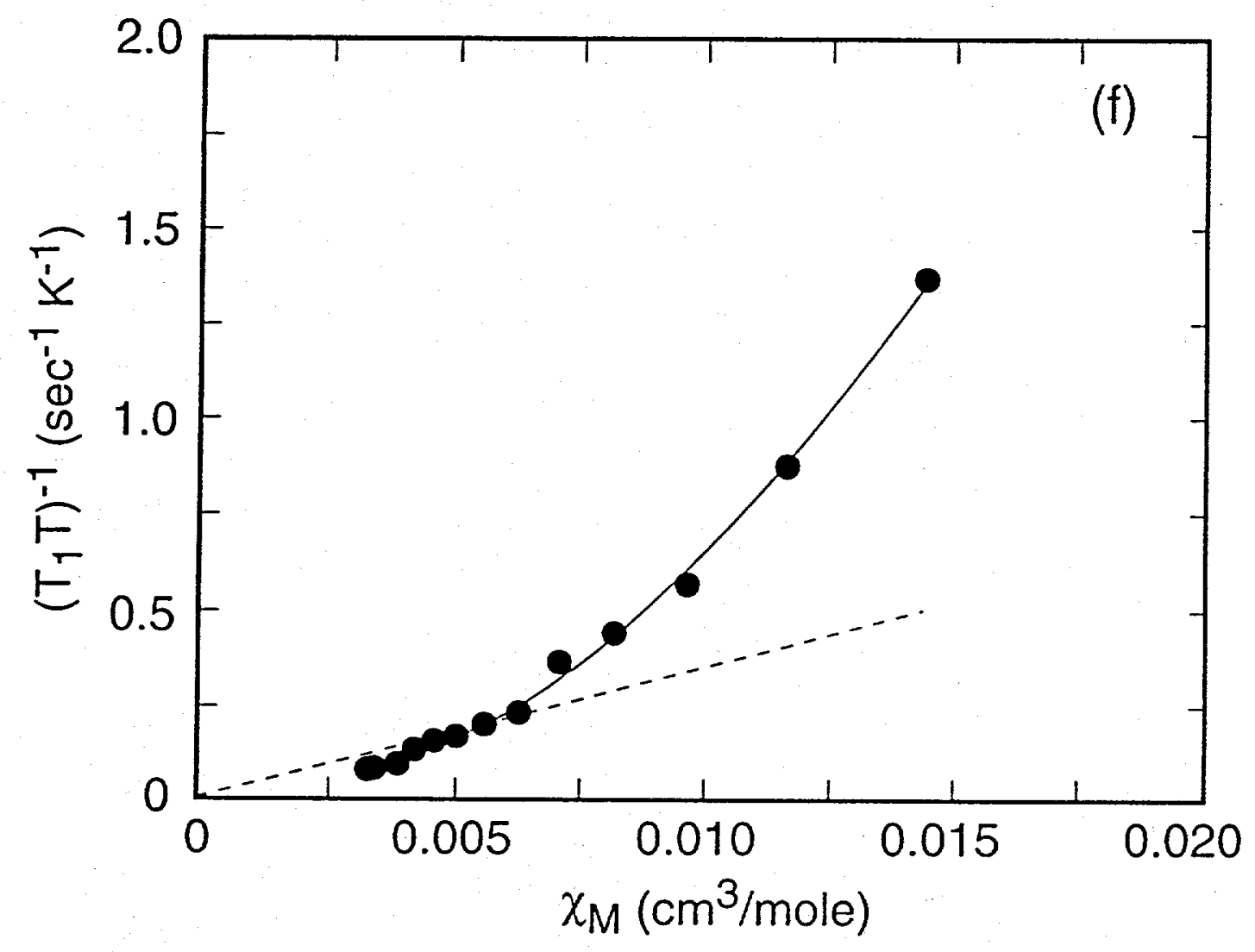

Figure 2(f) 


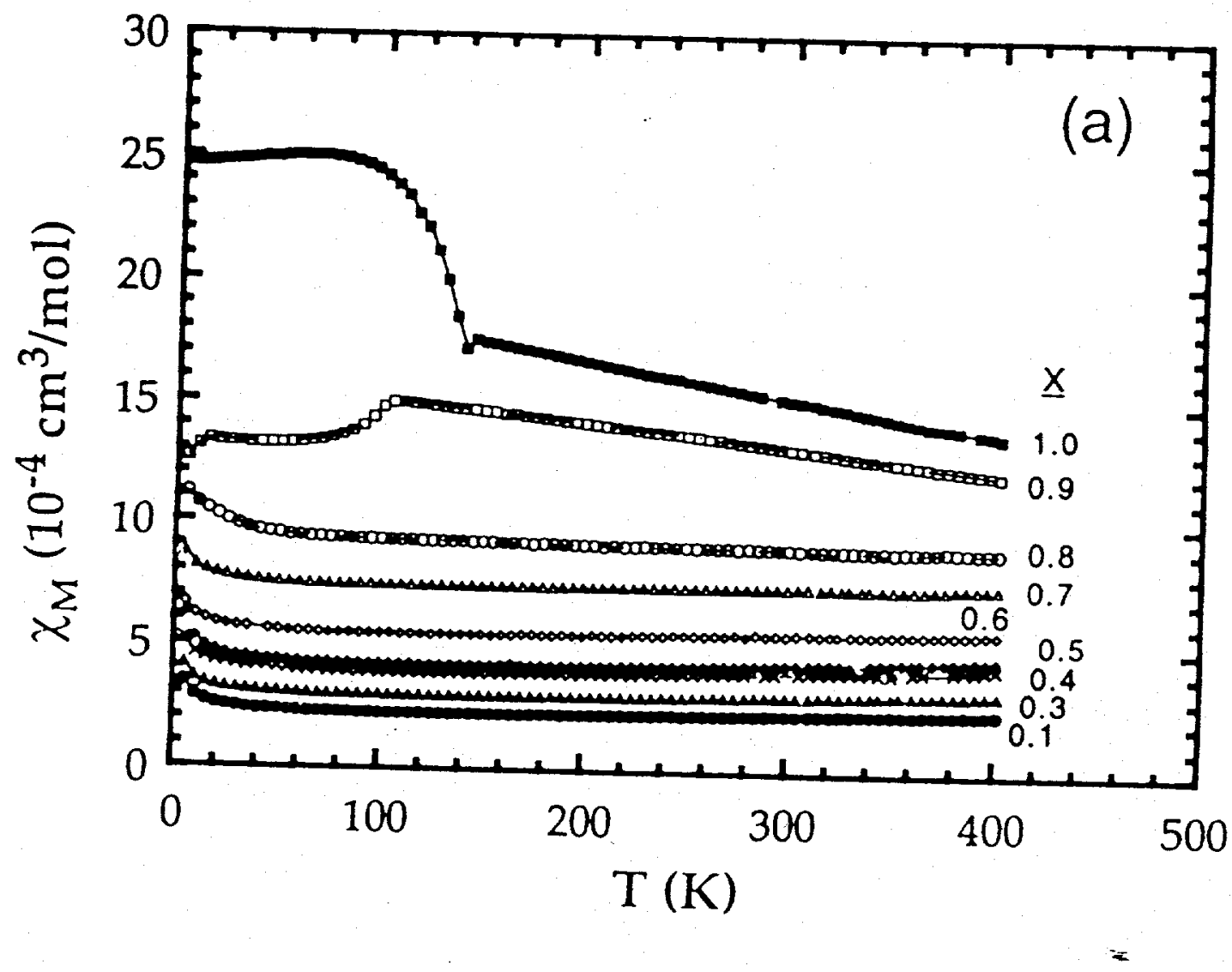

Figure 3(a) 


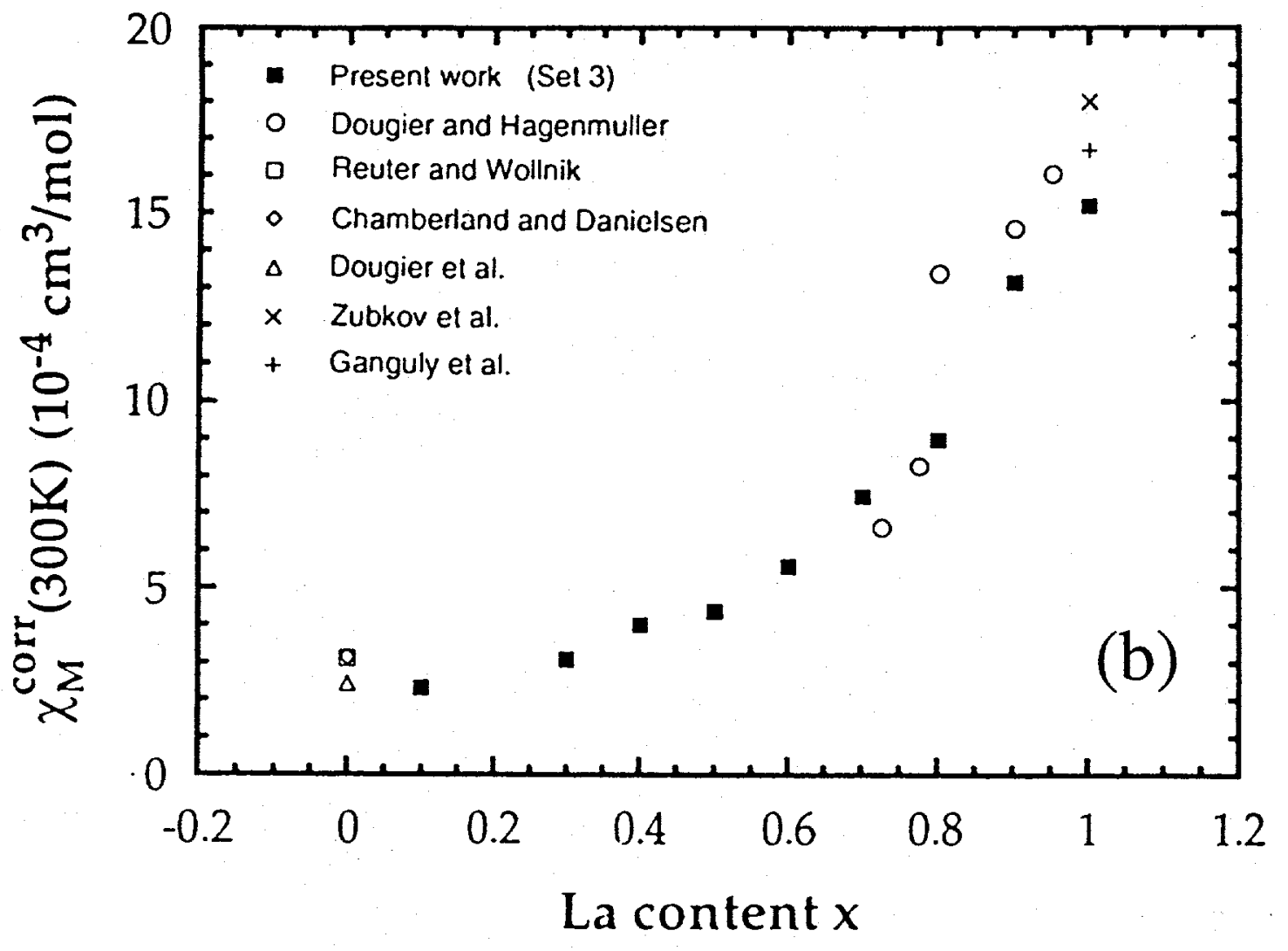

$-2$

Figure 3(b) 


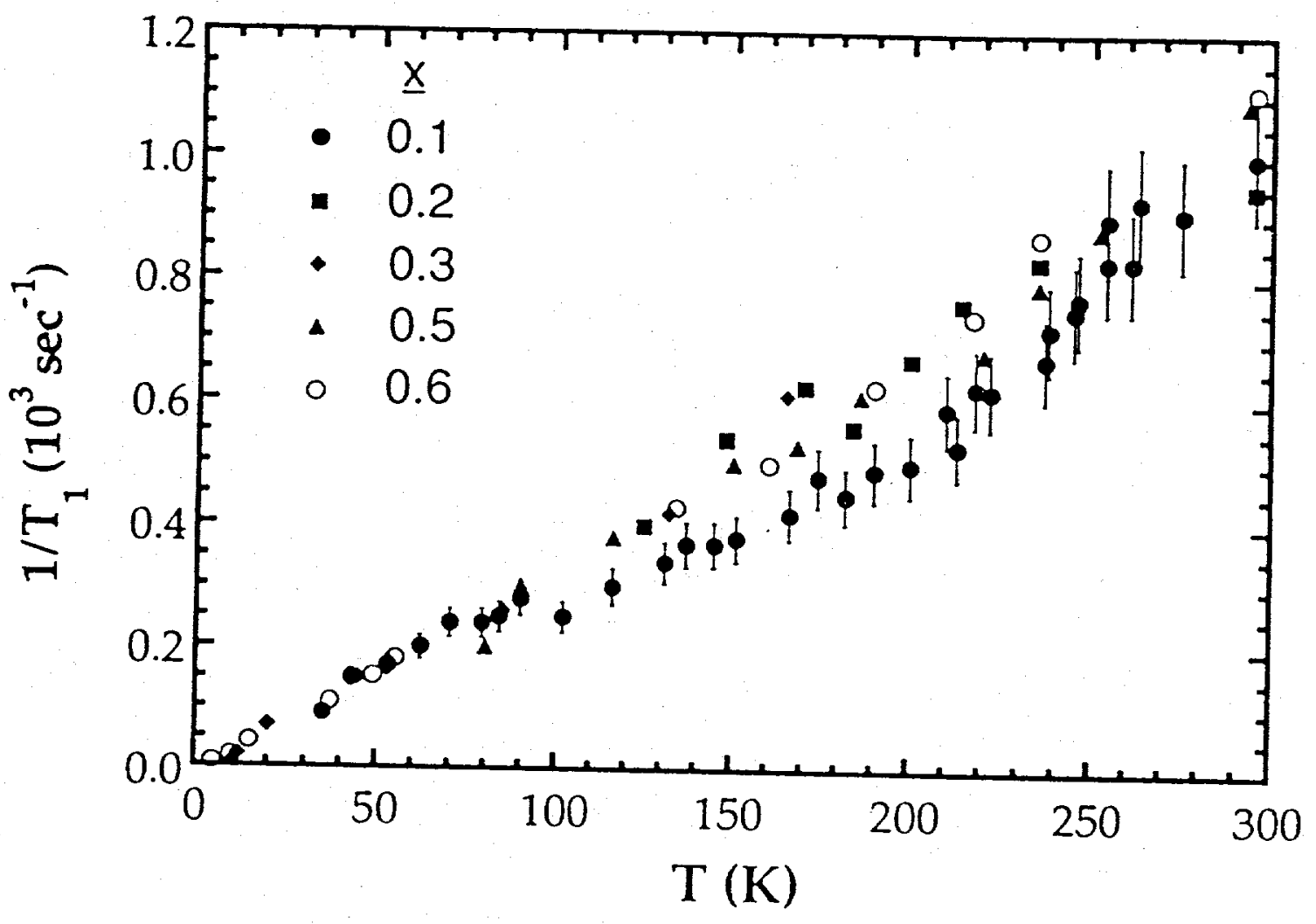

Figure 4 
$z=7 / 8$

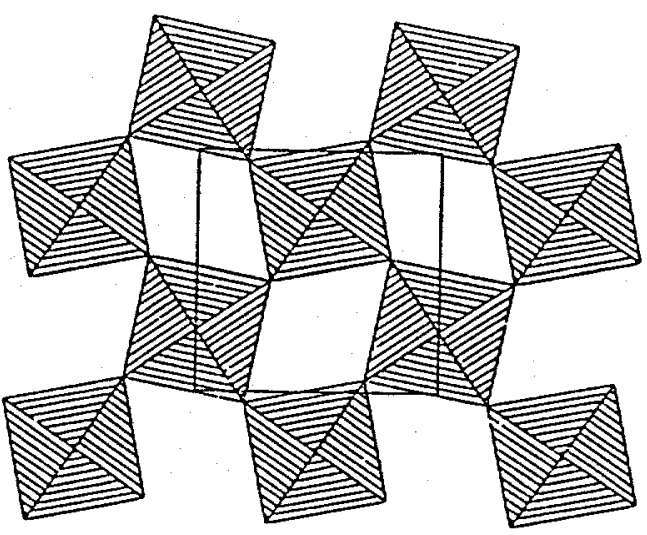

$z=5 / 8$

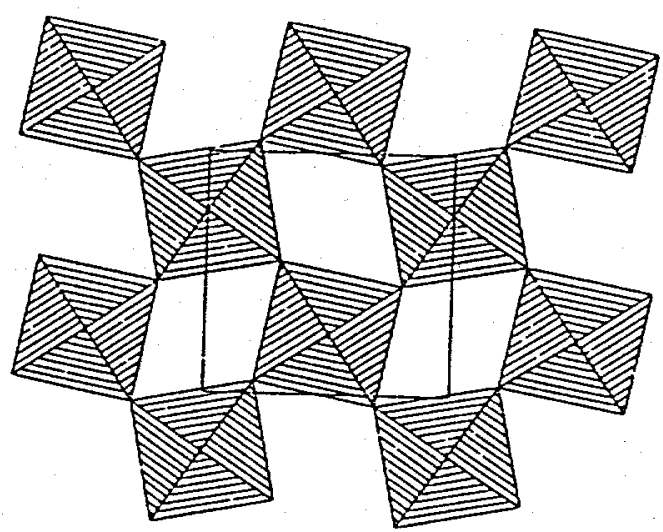

$z=3 / 8$

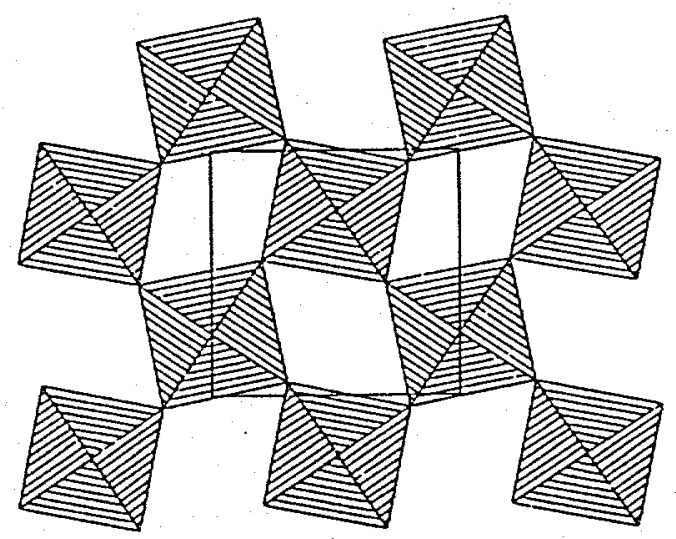

Figure 5 

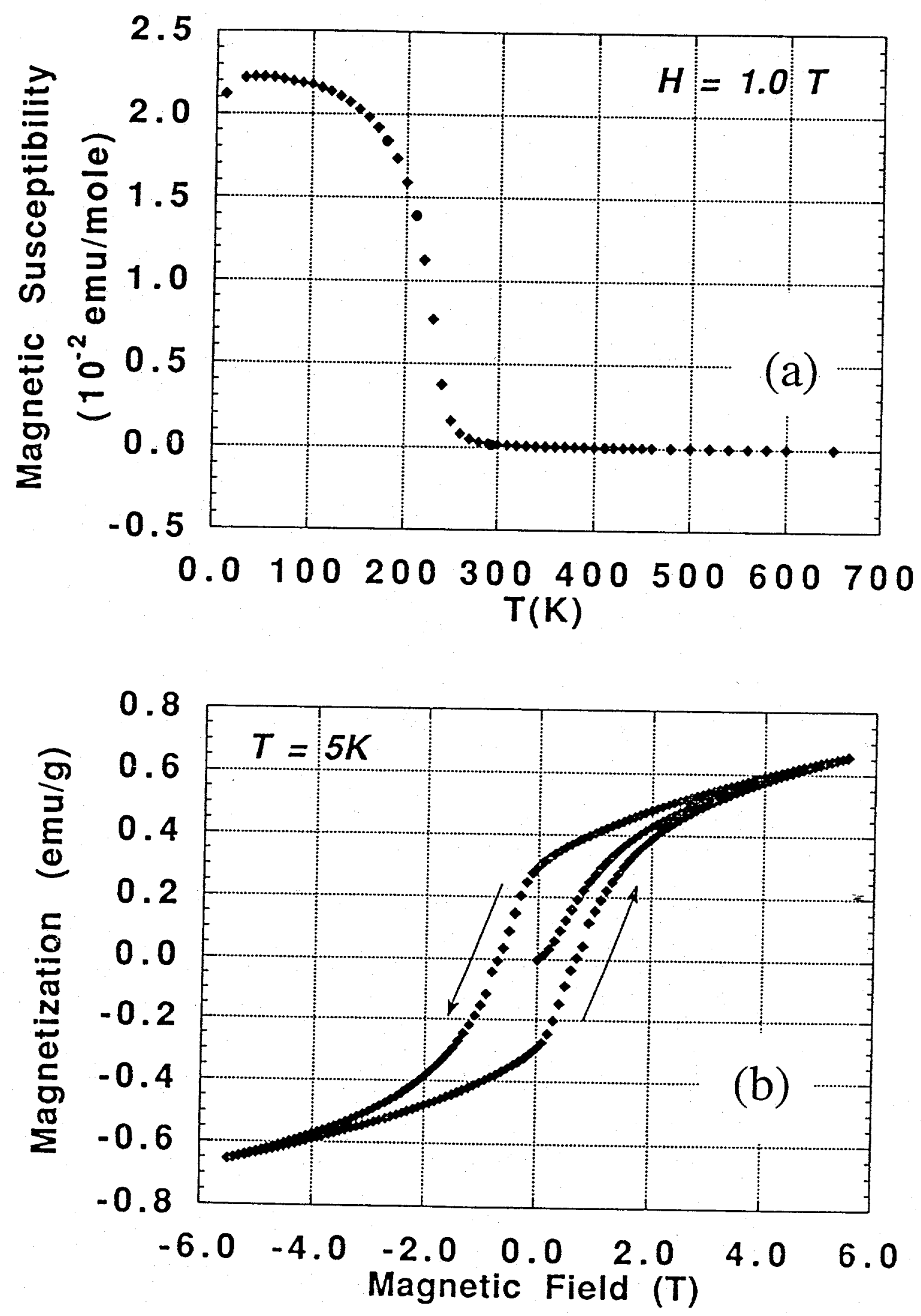

Figure 6 


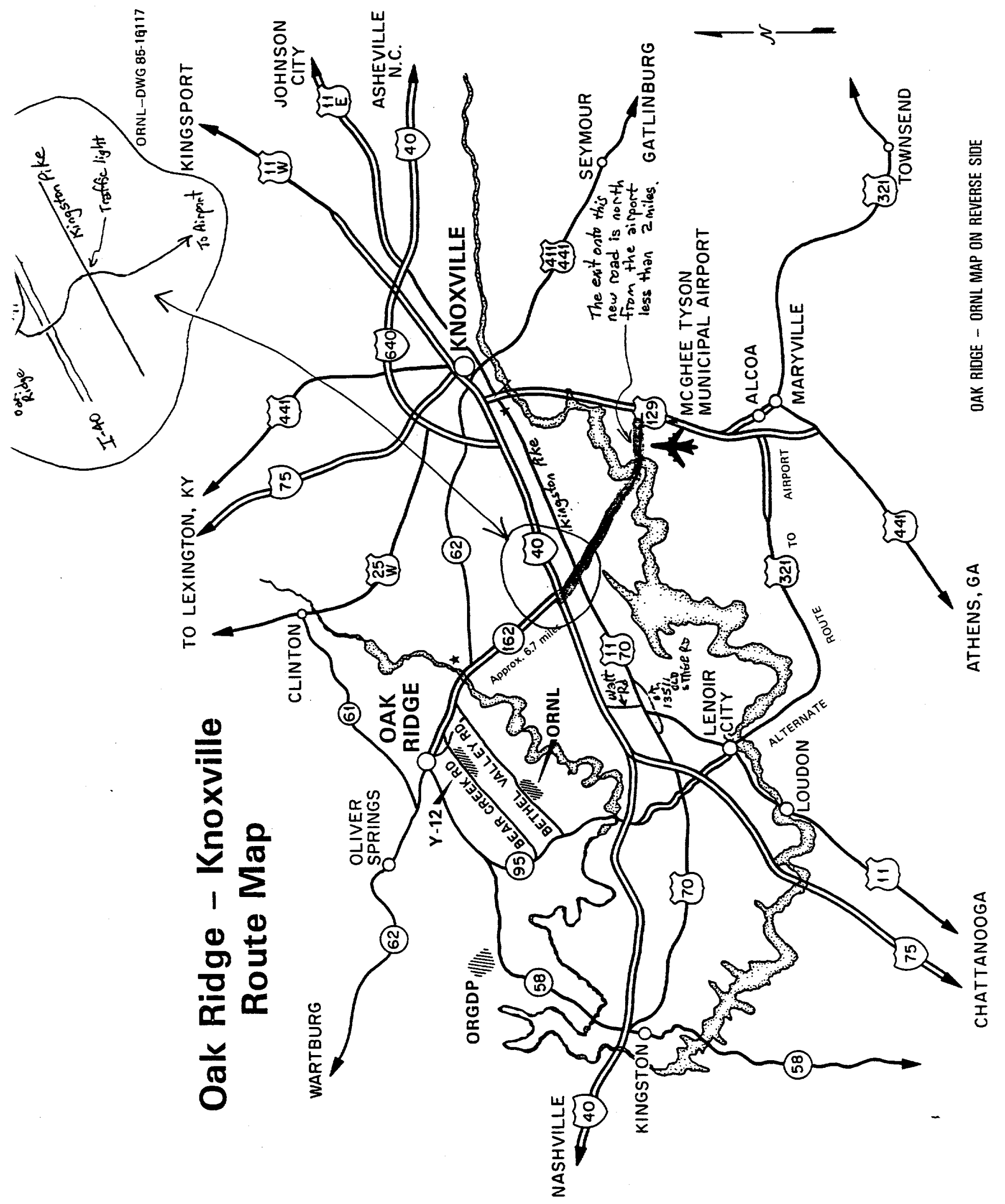

